\title{
Gambogic Acid Inhibits Malignant Melanoma Cell Proliferation Through Mitochondrial p66sh/ROS-p53/Bax- Mediated Apoptosis
}

\author{
Lili Liang $^{\text {a }}$ Zhixin Zhang \\ aDepartment of Dermatology, Shanxi Provincial People's Hospital, Taiyuan, 'Department of Surgery, \\ Shanxi Provincial Traditional Chinese Medicine Institute, Taiyuan, China
}

\section{Key Words}

Gambogic acid $\bullet$ Melanoma $\cdot$ Apoptosis $\cdot$ p66 $6^{\text {shc }} \cdot$ ROS $・$ p53

\begin{abstract}
Background/Aims: Malignant melanoma has high metastatic potential, is highly resistant to chemotherapy, and has a poor survival rate. Gambogic acid (GA), a polyprenylated xanthone extracted from a traditional Chinese medicinal herb, has been proven to exhibit antitumor activity. The present study aimed to investigate the signaling pathways that mediated GAinduced inhibition of human malignant skin melanoma proliferation. Methods: The study was conducted using A375 cells and the corresponding tumor transplanted in nude mice. Results: Incubation of A375 cells with $1-10 \mu \mathrm{g} / \mathrm{ml}$ GA decreased cell viability and increased apoptosis. GA concentration-dependently increased $p 66^{\text {shc }}$ expression and intracellular ROS levels. GA also decreased the oxygen consumption rate and the mitochondrial membrane potential (MMP) in A375 cells. Experimental inhibition of p66 shc by siRNA suppressed GAinduced increase of ROS, decrease of oxygen consumption rate, MMP and cell viability, whilst suppressing GA-induced increase of apoptosis. GA concentration-dependently upregulated p53 and Bax expression in A375 cells. GA also increased p53-TA-luciferase activity and p53binding to Bax promoter, which was inhibited by Sip53. Experimental inhibition of p53 with Sip53 blocked GA-induced decrease of the oxygen consumption rate and cell viability, and blocked the increase of apoptosis. In tumor-bearing nude mice, GA notably inhibited tumor growth, and this action was suppressed by $\mathrm{N}$-acetylcysteine (NAC), a potent antioxidant, and by PFT- $\alpha$, a p53 inhibitor. In A375 tumors transplanted in nude mice, GA increased both p $66^{\text {shc }}$ and $\mathrm{p} 53$ expression. NAC and PFT- $\alpha$ treatment did not significantly affect p66 ${ }^{\text {shc }}$ expression in tumors grown in mice treated with GA. In contrast, both NAC and PFT- $\alpha$ treatment inhibited GA-induced p53 expression in mouse tumors. Conclusion: Results provided novel preclinical insights into the chemotherapeutic use of GA by highlighting the importance of p66 shc/ ROS-p53/Bax pathways in the antitumor effect of GA in malignant melanoma.
\end{abstract}




\section{Cellular Physiology Cell Physiol Biochem 2016;38:1618-1630

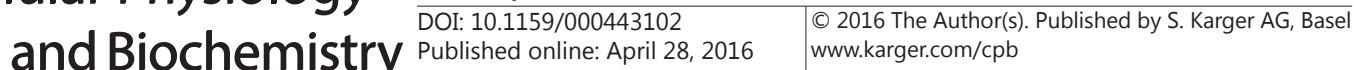 \\ Liang/Zhang: Gambogic Acid Inhibits Melanoma via P66-ROS-p53 Pathway}

\section{Introduction}

Malignant melanoma is an aggressive form of cancer that derives from the transformation of melanocytes in skin, mucous membranes, eyes or central nervous system [1-3]. In recent decades, the incidence of melanoma has dramatically increased, with 20,000 new cases diagnosed each year in China [4]. It is well-known that melanoma has high metastatic potential, is highly resistant to chemotherapy and has a poor survival rate [5]. In recent years, many chemo- and immune-based therapies for melanoma treatment have been evaluated in clinical trials [6]. However, most of these therapies failed to show significant benefit in melanoma patients [7-9] and hence there is an urgent need to find more effective agents for treatment of malignant melanoma.

Gambogic acid (GA) is a polyprenylated xanthone which is mainly extracted from the traditional Chinese medicinal herb Garcinia hanburyi Hook. f. [10]. GA has been widely used in China for homeostasis, detoxification, and anti-inflammatory action [11]. In recent years, a large amount of evidence has shown that GA exhibits antitumor effects in various types of cancers, including hepatoma, lung, epithelial cervical, prostate, pancreatic, and gastric tumors [12-17]. For example, GA was discovered to inhibit angiogenesis and prostate tumor growth by suppressing vascular endothelial growth factor receptor 2 signaling [12]. Wang et al. found that GA-loaded magnetic $\mathrm{Fe}_{3} \mathrm{O}_{4}$ nanoparticles could inhibit proliferation and migration of Panc-1 pancreatic cancer cells [13]. It was also shown that GA inhibited tumor growth, induced apoptosis, and could overcome drug resistance in human colorectal cancer cells [15]. The antitumor effect of GA is relatively specific for cancer cells and has minimal toxicity in normal cells [15]. GA has been authorized by the China Food and Drug Administration for phase II clinical trial in solid tumor therapy [18]. Recently, it was shown that GA possessed inhibitory activity in malignant melanoma [19, 20]. Zhao et al. found that GA induced reduction of lung colonization by B16-F10 melanoma cells in C57BL/6 mice [20]. Xu et al. showed that GA induced apoptosis by regulating the expression of Bax and Bcl2 and enhancing caspase- 3 activity in human malignant melanoma A375 cells [19]. However, the molecular mechanism underlying GA-induced antitumor effect in malignant melanoma is largely unknown.

The present study was designed to investigate the signaling pathways that mediated GA-induced inhibition of proliferation in malignant skin melanoma A375 cells, and growth inhibition of tumors transplanted in nude mice. Our results provided new insights into the molecular mechanisms underlying GA-induced apoptosis in malignant melanoma cells.

\section{Materials and Methods}

\section{Chemicals and reagents}

$\beta$-actin antibody was purchased from Santa Cruz Biotechnology (Santa Cruz, CA, USA). p66 $6^{\text {shc }}$ antibody, Trypsin-EDTA, Pierce ECL, TurboFect transfection reagent, Pierce Agarose ChIP Kit and BCA assay kit were purchased from Thermo Scientific (Rockford, IL, USA). pp53-TA-luciferase was purchased from Beyotime Institute of Biotechnology (Nantong, China). Renilla TK luciferase and Dual-Luciferase Reporter Assay System were purchased from Promega Corporation (Madison, WI, USA). p53 antibody was obtained from Cell Signaling Technology (Danvers, MA, USA). GA ( $\geqq 95 \%)$, NAC, PFT- $\alpha$, tBHP, MTT and DCFH-DA were obtained from Sigma-Aldrich (St. Louis, MO, USA). MitoSOX and Rhodamine 123 were purchased from Invitrogen (Carlsbad, CA, USA). TUNEL assay kit was purchased from Roche Diagnostics (Indiana, IN, USA). RNA isolation, cDNA transcription synthesis and real-time PCR kits were purchased from TaKaRa Bio (Osaka, Japan). Fetal bovine serum (FBS) was obtained from Gibco (Auckland, NZ). Penicillin-streptomycin was obtained from Life Technologies (Grand Island, NY, USA). All of the other chemicals used were of the highest grade available commercially.

Cell culture and treatment

The human skin melanoma cell line A375 was obtained from the American Type Culture Collection (ATCC, Manassas, VA, USA) and was maintained in RPMI-1640 supplemented with 10\% FBS, $100 \mathrm{U} / \mathrm{ml}$ 


\section{Cellular Physiology Cell Physiol Biochem 2016;38:1618-1630 \begin{tabular}{l|l} 
and Biochemistry Published online: April 28, 2016 & $\begin{array}{l}\text { D) } 2016 \text { The Author(s). Published by S. Karger AG, Basel } \\
\text { www.karger.com/cpb }\end{array}$ \\
\hline
\end{tabular} \\ Liang/Zhang: Gambogic Acid Inhibits Melanoma via P66-ROS-p53 Pathway}

penicillin $\mathrm{G}$ and $100 \mu \mathrm{g} / \mathrm{ml}$ streptomycin sulphate, in $5 \% \mathrm{CO}_{2}$-humidified atmosphere, at $37^{\circ} \mathrm{C}$. When cells were around 90\% confluent, Trypsin-EDTA $(0.25 \% / 0.02 \%)$ was used to passage cells. Passage 3-10 cells were used in the current study. The doubling time of A375 cells was 18-20 h. GA was dissolved in DMSO (10 $\mathrm{mg} / \mathrm{ml}$ stock solution) and was further diluted in RPMI-1640 without serum (the dilution range of DMSO: 1:1000-1:10,000). A375 cells were incubated with 1-10 $\mu \mathrm{g} / \mathrm{ml}$ GA for 12-36 $\mathrm{h}$ for evaluating the concentration-dependent effect of GA; for assessing the concentration-dependent effect of GA on apoptosis, ROS generation, mitochondrial function and the expression of key regulators, A375 cells were incubated with 1-10 $\mathrm{mg} / \mathrm{ml}$ GA for $24 \mathrm{~h}$. cells were transfected with siRNAs for $48 \mathrm{~h}$ (see the section "Transfection and reporter gene assay") and then exposed to $10 \mu \mathrm{g} / \mathrm{ml} \mathrm{GA}$ in presence or absence of $100 \mu \mathrm{M}$ NAC for examining the molecular mechanism of GA-induced cytotoxicity on melanoma cells.

\section{Cell viability and proliferation}

A375 cells were seeded in 96-well plates, $1 \times 10^{4}$ cells per well. After $24 \mathrm{~h}$ incubation, cells were treated with 1-10 $\mathrm{gg} / \mathrm{ml}$ GA for additional 12-36 h. In some experiments, 30\% confluent cells were transfected with indicated siRNAs for $48 \mathrm{~h}$ (see the section "Transfection and reporter gene assay") and then exposed to $10 \mu \mathrm{g} / \mathrm{ml}$ GA for additional $24 \mathrm{~h}$. After treatment, cell viability/proliferation was determined by the 3-(4, 5-dimethylthiazoyl-2-yl) 2, 5 diphenyltetrazolium bromide (MTT) assay which evidenced the amount of metabolically active cells in culture using a microplate reader (TECAN, Infinite ${ }^{\circledR}$ F200 PRO, Switzerland). Control cells were treated with serum-free RPMI-1640 with DMSO and/or scramble siRNAs.

\section{Apoptosis}

Terminal deoxynucleotidyl transferase-mediated dUTP nick end labeling (TUNEL) assay was conducted as previously described to determine apoptosis [21]. Cells were seeded in special dishes for confocal observation. A375 cells at 60-70\% confluence (24 h after seeding) were incubated with 1-10 $\mu \mathrm{g} /$ $\mathrm{ml}$ GA for additional $24 \mathrm{~h}$. In some experiments, 30\% confluent cells were transfected with indicated siRNAs for $48 \mathrm{~h}$ (see the section "Transfection and reporter gene assay") and then exposed to $10 \mu \mathrm{g} / \mathrm{ml}$ GA for 24 h. After treatment, cells were washed with phosphate-bufferedsaline (PBS), fixed in 4\% paraformaldehyde, and then incubated with $3 \% \mathrm{H}_{2} \mathrm{O}_{2}$ in methanol for $10 \mathrm{~min}$ at room temperature in order to block endogenous peroxidase activity. After washing with PBS, cells were incubated with the TUNEL reaction mixture for $1 \mathrm{~h}$ at $37^{\circ} \mathrm{C}$, and then stained with Hoechst for $10 \mathrm{~min}$ at room temperature. Finally, TUNEL-positive cells (green fluorescence) were observed and counted using a confocal microscopy (Olympus, FV10i, Japan). Results were shown as percentage of TUNEL-positive cells in treated samples versus control. Control cells were treated with serum-free RPMI-1640 with DMSO and/or scramble siRNAs.

\section{Determination of ROS}

Intracellular ROS level in A375 cells was determined using the oxidation-sensitive probe DCFH-DA. Cells were treated as stated in "Cell culture and treatment" section. After treatment, cells were trypnisized, collected and re-suspended in serum-free RPMI-1640 medium with $10 \mu \mathrm{M}$ DCFH-DA (10 mM stock solution in DMSO) for $60 \mathrm{~min}$ at $37^{\circ} \mathrm{C}$. After washing cells for 3 times with PBS, fluorescence was analyzed by flow cytometry (BD Accuri, C6, USA) using C6 Flow Cytometer ${ }^{\circledR}$ System. 20,000 cells were analyzed per sample. The percentage of DCFH-DA-positive cells was calculated and results were shown as percentage of ROS level in treated samples versus non-treated samples (control). Control cells were treated with serum-free RPMI1640 with DMSO and/or scramble siRNAs.

In some experiments, mitochondrial ROS level was determined using the mitochondrial superoxidespecific probe MitoSOX. Cells were seeded in special dishes for confocal observation. 60-70\% confluent cells were treated with $10 \mu \mathrm{g} / \mathrm{ml}$ GA for $24 \mathrm{~h}$. After the experiment, cells were washed with PBS, and stained with $500 \mathrm{nM}$ MitoSOX ( $1 \mathrm{mM}$ stock solution in DMSO) for $30 \mathrm{~min}$ at $37^{\circ} \mathrm{C}$, and then observed using a confocal microscopy (Olympus, FV10i, Japan; excitation/emission, 535/617 nm). The percentage of MitoSOX-positive cells (red fluorescence) was determined.

\section{Real time-polymerase chain reaction (RT-PCR)}

Total RNA was isolated from A375 cells according to the manufacturer's instructions (TaKaRa, Japan). The concentration of total RNA was determined by spectrophotometry (TECAN, Infinite $₫$ F200 PRO microplate reader, Switzerland). Then, 500 ng RNA were reverse-transcribed to cDNA using a cDNA 


\section{Cellular Physiology Cell Physiol Biochem 2016;38:1618-1630 \begin{tabular}{l|l} 
and Biochemistry Published online: April 28, 2016 & $\begin{array}{l}\text { Do } 2016 \text { The Author(s). Published by S. Karger AG, Basel } \\
\text { www.karger.com/cpb }\end{array}$ \\
\hline
\end{tabular} \\ Liang/Zhang: Gambogic Acid Inhibits Melanoma via P66-ROS-p53 Pathway}

synthesis kit (TaKaRa, Japan). The samples were analyzed by RT-PCR using the BIORAD System (CFX96, USA) for quantitative evaluation of RT-PCR. One microliter of cDNA was amplified with SYBR Premix Ex Taq (TaKaRa, Japan).

\section{Western blot}

Cells were treated as stated in "Cell culture and treatment" section. After the experiment, cells or tumor tissues (see the section "Animal treatment") were lysed on ice for 30 min with cell lysis buffer (50 mM Tris-HCl, pH 8.0, $150 \mathrm{mM} \mathrm{NaCl}, 1 \%$ Triton X-100, $1 \mathrm{mM}$ EDTA, $10 \mathrm{mM} \mathrm{NaF}, 1 \mathrm{mM} \mathrm{Na} \mathrm{VO}_{4}$, and protease inhibitor cocktail). After centrifugation at $20,000 \times \mathrm{g}$ for $20 \mathrm{~min}$ at $4{ }^{\circ} \mathrm{C}$, the protein content in supernatants was determined using the BCA assay kit. Thereafter, equal volumes of supernatant and $2 \times$ SDS loading buffer were mixed and boiled for $5 \mathrm{~min} .20 \mu \mathrm{g}$ of total proteins were subjected to SDS-PAGE (spacer gel, $80 \mathrm{~V}$; separation gel, $130 \mathrm{~V}$ ) and then transferred onto a PVDF membrane (25 V, $30 \mathrm{~min})$. After blocking (8\% nonfat milk) for $1 \mathrm{~h}$ in room temperature, the membranes were incubated overnight at $4^{\circ} \mathrm{C}$ with the indicated primary antibodies. After washing for four times, the membrane was incubated at $37^{\circ} \mathrm{C}$ for 30 min with appropriate horseradish peroxidase-conjugated secondary antibodies. The protein bands were visualized using chemiluminescent reagents (Pierce ECL) according to the manufacturer's instructions, and quantified using the image analyzer QuantityOne System (Bio-Rad, Richmond, CA, USA).

\section{Determination of mitochondrial function}

The mitochondrial function was determined by assessing the oxygen consumption rate and the MMP. Cells were treated as stated in "Cell culture and treatment" section. After the experiment, cultured cells were trypsinized, washed in PBS and then resuspended in oxygen-saturated Dulbecco's phosphate-buffered saline (dPBS). Then, the oxygen consumption rate was measured with a Clark Oxygen Electrode (Hansatech, UK) and expressed as percentage of baseline in each group. For the determination of MMP, cells were seeded in dishes used for confocal observation. Cells treated by $200 \mu \mathrm{M}$ tert-Butyl hydroperoxide (tBHP) for 24 $\mathrm{h}$ were used as positive control. After treatment, cells were washed with PBS, and incubated with $10 \mu \mathrm{M}$ Rhodamine 123 (Rho123) at $37^{\circ} \mathrm{C}$ for $30 \mathrm{~min}$. Thereafter, fluorescence was observed under a confocal microscopy (Olympus, FV10i, Japan; excitation/emission, 488/533 nm) and representative images were shown.

\section{Transfection and reporter gene assay}

siRNAs of p66 and p53 and scramble control siRNAs were synthesized by Genechem Technology (Shanghai, China). siRNAs, pp53-TA-luciferase, and Renilla TKluciferase plasmids were transfected into A375 cells. The transfection was conducted using TurboFect transfection reagent according the manufacturer's protocols. After the experiments, cells were harvested in passive lysis buffer and the reporter assay was performed using the Dual-Luciferase Reporter Assay System. Firefly luciferase activity was normalized to Renilla luciferase and shown as ratio of relative light units.

\section{Chromatin Immunoprecipitations}

The activity of p53 binding to Bax promoter was detected by the Chromatin Immunoprecipitations (CHIP) assay using the Pierce Agarose ChIP Kit according to the manufacturer's instructions. Cells were cross-linked using 1\% formaldehyde, and were then harvested and sheared by sonication. The cell lysate was immunoprecipitated with p53 antibodies. DNA was isolated from the immunoprecipitated chromatin, and PCR was performed to examine the presence of the Bax gene promoter using BIORAD System (CFX96, USA).

\section{Animal treatment}

The tumor animal model was established as previously described [22]. Briefly, male nude mice (6-8 weeks) were obtained from the Animal Centre of Shanxi Medical University. The Animal Care and Use Committee of Shanxi Provincial Traditional Chinese Medicine Institute approved surgical procedures in accordance with the National guidelines regarding the care and use of animals for experimental procedures.

A375 tumor cells $\left(1 \times 10^{5}\right.$ cells in $\left.100 \mu \mathrm{lBS}\right)$ were implanted subcutaneously into nude mice. Our preliminary results have shown that 5 days after implantation of A375 cells the tumor grew to a volume of about $100 \mathrm{~mm}^{3}$. Mice were then randomly divided into four groups with six mice per group as follows: 
Control: untreated mice that received vehicle (10\% DMSO, 15\% ethanol and 75\% PBS); GA: mice that received intraperitoneal injection of $100 \mathrm{mg} / \mathrm{kg} \mathrm{GA}(10 \%$ DMSO, $15 \%$ ethanol and 75\% PBS); GA+NAC: mice that received intraperitoneal injection of $100 \mathrm{mg} / \mathrm{kg} \mathrm{GA}$ plus $10 \mathrm{mg} / \mathrm{kg} \mathrm{N}$-acetylcysteine; GA+PFT- $\alpha$ : mice that received intraperitoneal injection of $100 \mathrm{mg} / \mathrm{kg} \mathrm{GA}$ plus $10 \mathrm{mg} / \mathrm{kg}$ PFT- $\alpha$. All mice were sacrificed at day 11 after treatment. Subcutaneous tumors were then excised, and tumor diameter was measured using a Vernier caliper. Tumor volume was calculated by the formula $V=\pi / 6 \times L \times S^{2}$, where $L$ and $S$ are the long and short diameters of the tumor.

\section{Statistical analysis}

All statistical analysis was performed using the GraphPad software (GraphPad Prism 5.0). Results were expressed as mean \pm standard error of the mean (SEM). Statistical analysis was carried out by one-way analysis of variance (ANOVA) followed by the Newmane Keuls multiple-comparison post hoc test. $P$ value< 0.05 was considered statistically significant.

\section{Results}

GA inhibits proliferation and induces apoptosis in malignant melanoma cells

The concentration- and time-dependent effects exerted in vitro by GA on human malignant skin melanoma A375 cells were evaluated. To avoid the possible influence of serum, we used serum-free RPMI-1640 as culture medium. We wanted to state that starvation may result in metabolic stress in our experimental in vitro model and simulate nutrient deprivation in large or fast growing tumors [23]. Incubation of A375 cells with 1-10 $\mu \mathrm{g} / \mathrm{ml}$ GA decreased cell viability, the effect being concentration- and time-dependent (Fig. $1 \mathrm{~A}, \mathrm{~B}$ and $\mathrm{C}$ ). Incubation of cells with $10 \mu \mathrm{g} / \mathrm{ml} \mathrm{GA}$ for $24 \mathrm{~h}$ decreased cell viability to about

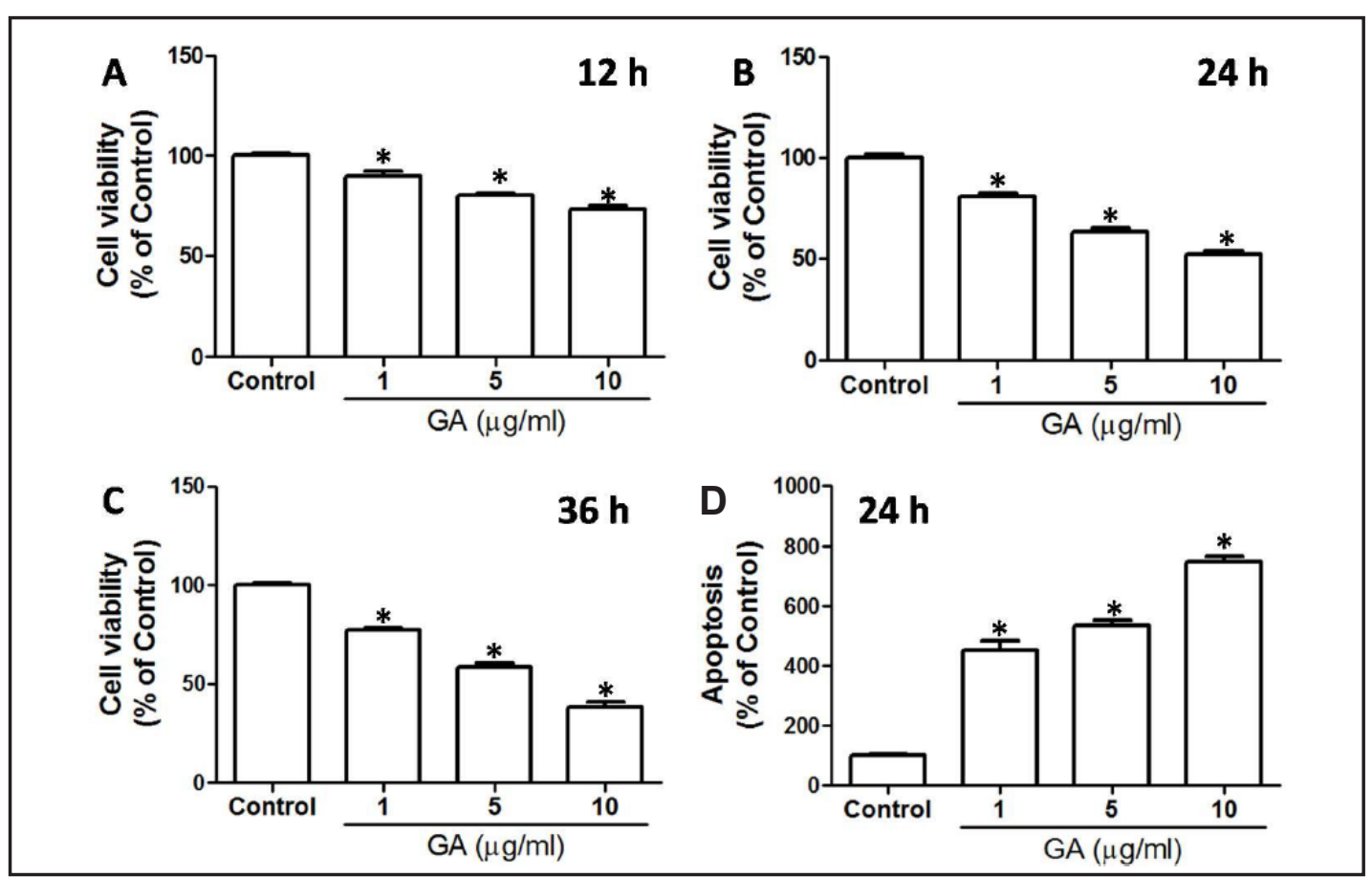

Fig. 1. The effect of GA on cell proliferation in A375 cells. (A, B and C) A375 cells were incubated with 1-10 $\mu \mathrm{g} / \mathrm{ml} \mathrm{GA}$ for 12-36 h. Control cells were treated with serum-free RPMI-1640 with DMSO. Cell viability was evaluated using the MTT assay. Results were expressed as percentage of Control. (D) A375 cells were incubated with 1-10 $\mathrm{\mu g} / \mathrm{ml} \mathrm{GA}$ for $24 \mathrm{~h}$. Control cells were treated with serum-free RPMI-1640 with DMSO. Apoptosis was then determined by the TUNEL assay. Results were expressed as percentage of Control. $* P<0.05$, compared with Control. 

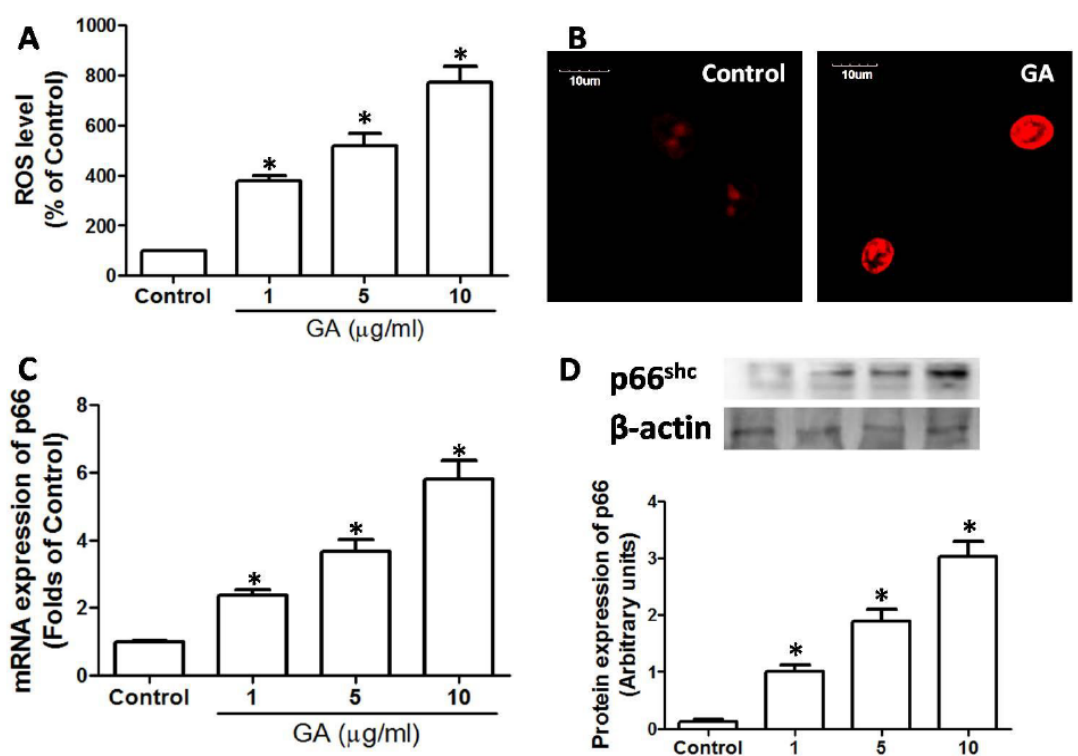

\section{D $66^{\text {shc }}$}

\section{B-actin}
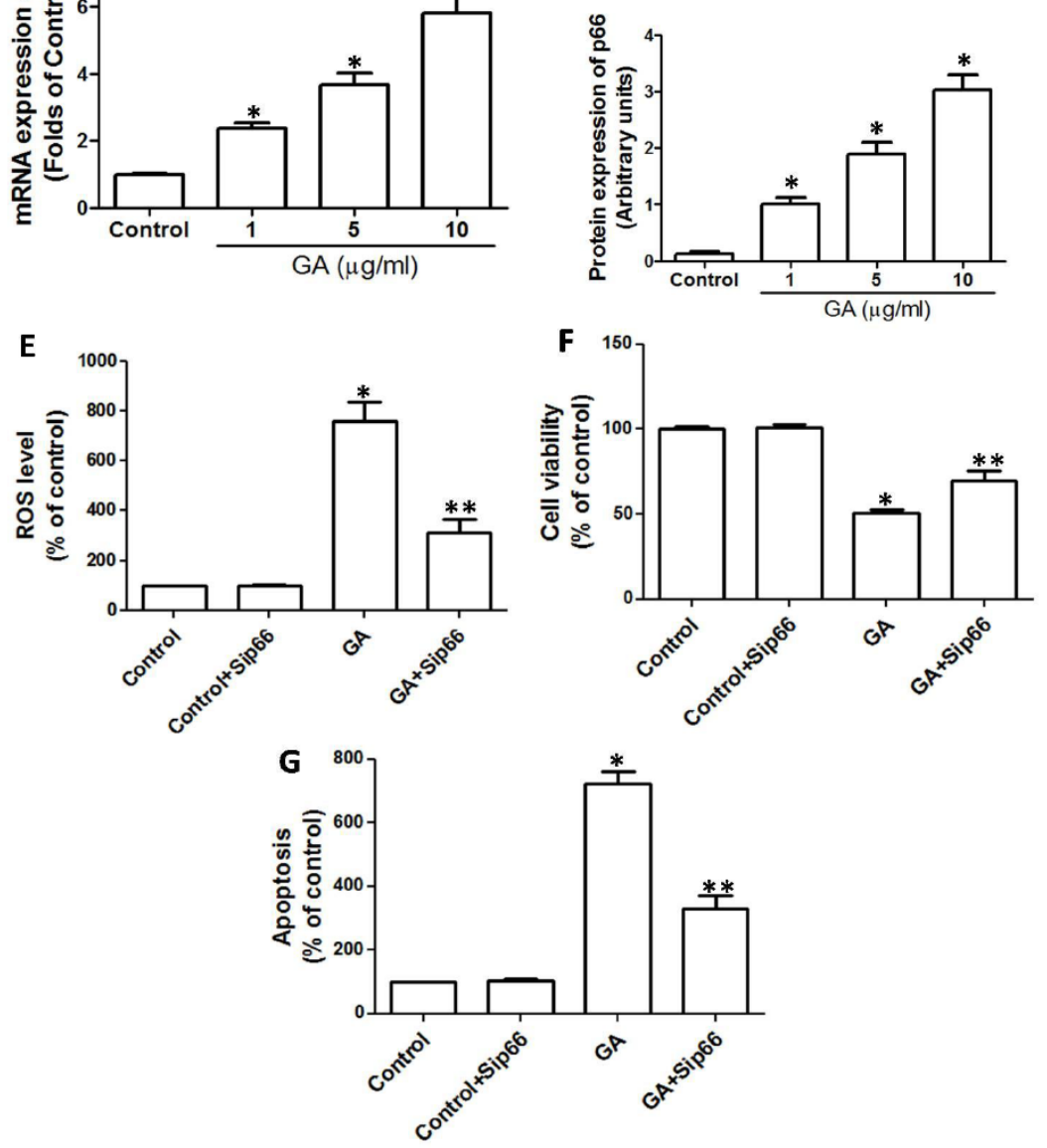

Fig. 2. The role of ROS generation and $\mathrm{p} 66^{\text {shc }}$ upregulation in GA-induced inhibition of A375 cell proliferation. (A, B C and D) A375 cells were incubated with 1-10 $\mu \mathrm{g} / \mathrm{ml}$ GA for $24 \mathrm{~h}$. Control cells were treated with serum-free RPMI-1640 with DMSO. Cells were incubated with $10 \mu \mathrm{M}$ DCFH-DA for 60 min in the dark and then analyzed by flow cytometry. Results were presented as percentage of Control (A). In other experiments, cells were stained with the mitochondrial superoxide specific probe MitoSOX $(10 \mu \mathrm{M})$ for 30 min in the dark, and fluorescence intensity was observed by confocal microscopy (B). mRNA (C) and protein (D) expression of $\mathrm{p} 66^{\text {shc }}$ were determined by real-time PCR and western blot, respectively. The results of real-time PCR were expressed as folds of Control. Representative blots of western blot were shown and results were also shown as ratio of p66 ${ }^{\text {shc }}$ band to $\beta$-actin band. (E, F and G) A375 cells were transfected with sip66. $48 \mathrm{~h}$ after the transfection, cells were treated with $10 \mu \mathrm{g} / \mathrm{ml}$ GA for $24 \mathrm{~h}$. Control cells were transfected with scramble siRNAs and treated with serum-free RPMI-1640 with DMSO. After treatment, intracellular ROS level was determined using DCFH-DA as oxidation indicator (E). Cell viability was measured by the MTT assay (F). Apoptosis was evaluated by the TUNEL assay (G). Results were shown as percentage of Control. $* P<0.05$, compared with Control.** $P<0.05$, compared with GA.

\section{KARGER}


Fig. 3. Role of $p 66^{\text {shc }}$ upregulation in GA-exhibited effect on mitochondrial dysfunction A375 cells. A375 cells were transfected with sip66 $6^{\text {shc }} .48 \mathrm{~h}$ after transfection, cells were treated with $10 \mu \mathrm{g} / \mathrm{ml} \mathrm{GA}$ for $24 \mathrm{~h}$. Control cells were transfected with scramble siRNAs and treated with serum-free RPMI-1640 with DMSO. After treatment, oxygen consumption rate was evaluated by a Clark Oxygen Electrode (A). Results were shown as rate of oxygen consumption. In some experiments, cells were incubated with Rho123 (10 $\mu \mathrm{M})$, and then fluorescence was observed by confocal microscopy. Cells treated by $200 \mu \mathrm{M}$ tBHP for $24 \mathrm{~h}$ were used as positive control. * $P<0.05$, compared with Control. ** $P<0.05$, compared with GA.

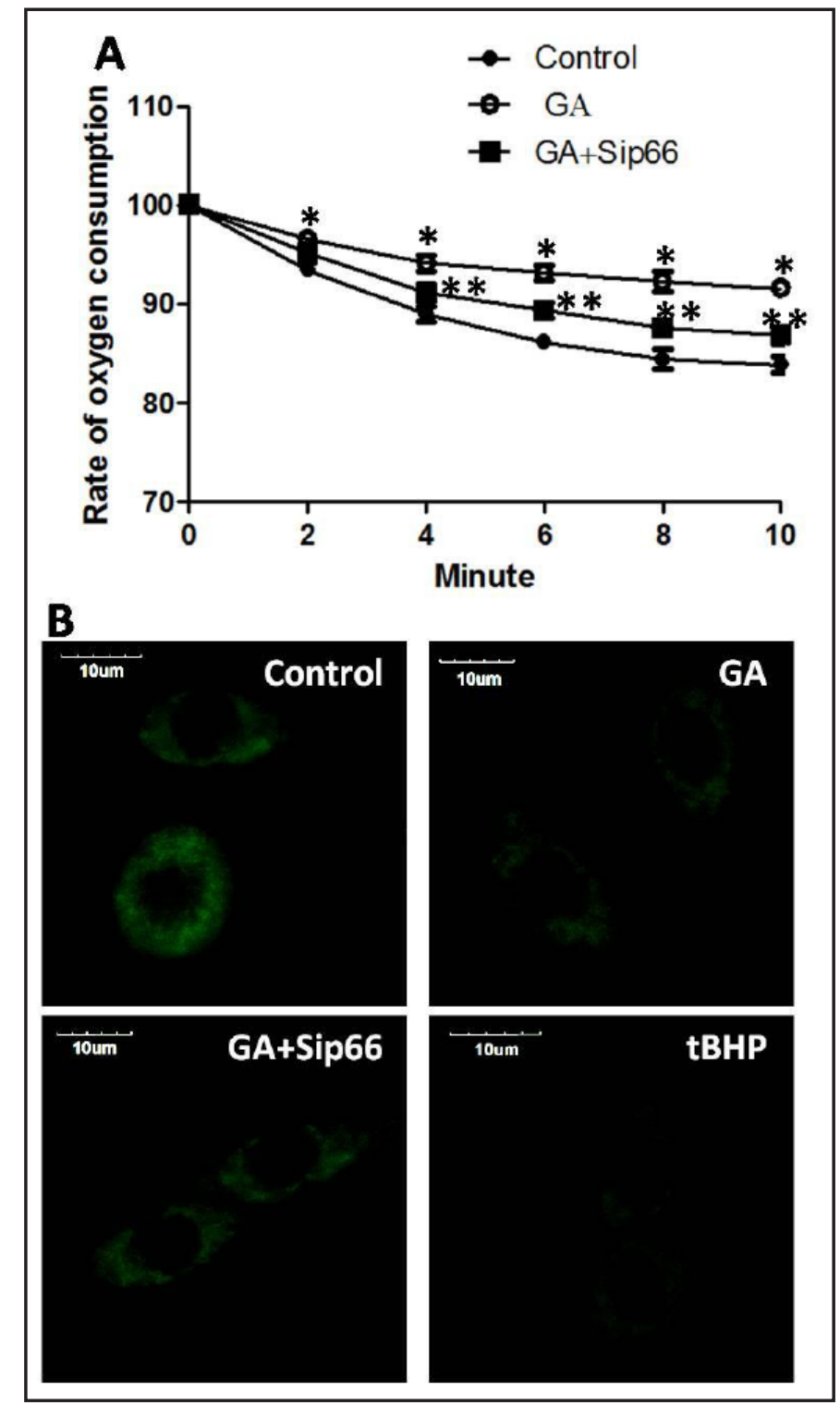

$50 \%$ of control, and this exposure model was selected throughout the study. The effect of GA on the apoptosis of A375 cells was investigated, and we showed that GA increased the percentage of TUNEL-positive cells in a concentration-dependent manner (Fig. 1D). Culture of cells for $24 \mathrm{~h}$ with $10 \mu \mathrm{g} / \mathrm{ml}$ GA decreased cell viability to about $50 \%$ of non-treated cells (Control), and increased apoptosis to about 8 times of Control. The concentration of 10 $\mu \mathrm{g} / \mathrm{ml} \mathrm{GA}$ was used throughout the following experiments for investigating the molecular mechanisms underlying the action of GA.

ROS generation and $p 66^{\text {shc }}$ upregulation are involved in GA-induced inhibition of A375 cell proliferation

To evaluate whether reactive oxygen species (ROS) generation was involved in GAinduced inhibition of A375 cell proliferation, the effect of GA on intracellular ROS levels was examined. The intracellular ROS level was increased by $24 \mathrm{~h}$ treatment with $10 \mu \mathrm{g} / \mathrm{ml} \mathrm{GA}$ in a concentration-dependent manner, as evidenced by the increase of DCFH-DA-positive cells (Fig. 2A). We also showed that GA increased MitoSOX-reactive A375 cells, indicating that GA induced the increase of mitochondrial superoxide generation (Fig. 2B). To test the mitochondrial source of GA-induced ROS generation, we examined the expression of $\mathrm{p} 66^{\text {shc }}$, 


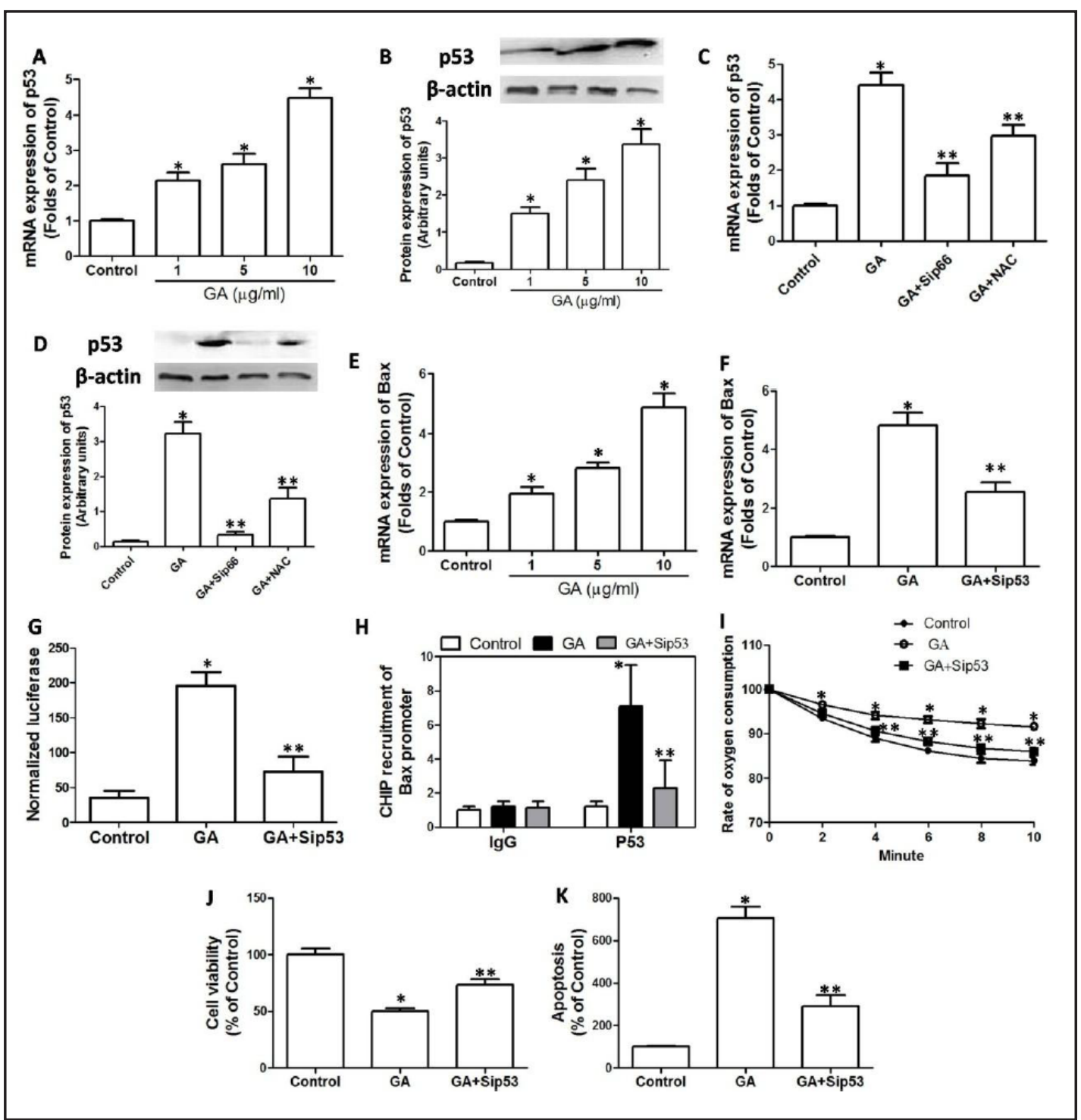

Fig. 4. Role of p53 upregulation in GA-induced inhibition of A375 cell proliferation. (A and B) A375 cells were incubated with 1-10 $\mu \mathrm{g} / \mathrm{ml}$ GA for $24 \mathrm{~h}$. (C and D) A375 cells were transfected with sip66 ${ }^{\text {shc }} .48 \mathrm{~h}$ after transfection, cells were treated for $24 \mathrm{~h}$ with $10 \mu \mathrm{g} / \mathrm{ml}$ GA in presence or absence of $100 \mu \mathrm{M} \mathrm{NAC}$. After treatment, real-time PCR (A and C) and western blot (B and D) were conducted to determine mRNA and protein expression of p53. The results of real-time PCR were expressed as folds of Control. Representative blots of western blot were shown and results were also shown as ratio of p53 band to $\beta$-actin band. (E) A375 cells were incubated with 1-10 $\mathrm{g} / \mathrm{ml}$ GA for $24 \mathrm{~h}$. After treatment, real-time PCR was conducted to determine mRNA of Bax. Results were expressed as folds of Control. (F-K) A375 cells were transfected with sip53. $48 \mathrm{~h}$ after transfection, cells were treated with $10 \mu \mathrm{g} / \mathrm{ml} \mathrm{GA}$ for $24 \mathrm{~h}$. After treatment, real-time PCR was conducted to determine the mRNA of Bax (F). Results were expressed as folds of Control. p53-TA-luciferase activity was determined with STOP\&GLO and firefly luciferase activity was normalized to Renilla luciferase (G). Binding of $\mathrm{p} 53$ to the Bax promoter was assessed by the CHIP assay $(\mathrm{H})$. The oxygen consumption rate was evaluated by a Clark Oxygen Electrode (I). Cell viability was determined by the MTT assay (J). Apoptosis was measured by TUNEL assay (K). ${ }^{*} P<0.05$, compared with Control. ${ }^{* *} P<0.05$, compared with GA.

an important mitochondrial stimulator of ROS generation [24]. Results showed that both mRNA and protein expression of p66 ${ }^{\text {shc }}$ was increased by GA treatment in a concentrationdependent manner (Fig. 2C and D). To examine the role of p66 ${ }^{\text {shc }}$ in GA-induced ROS 


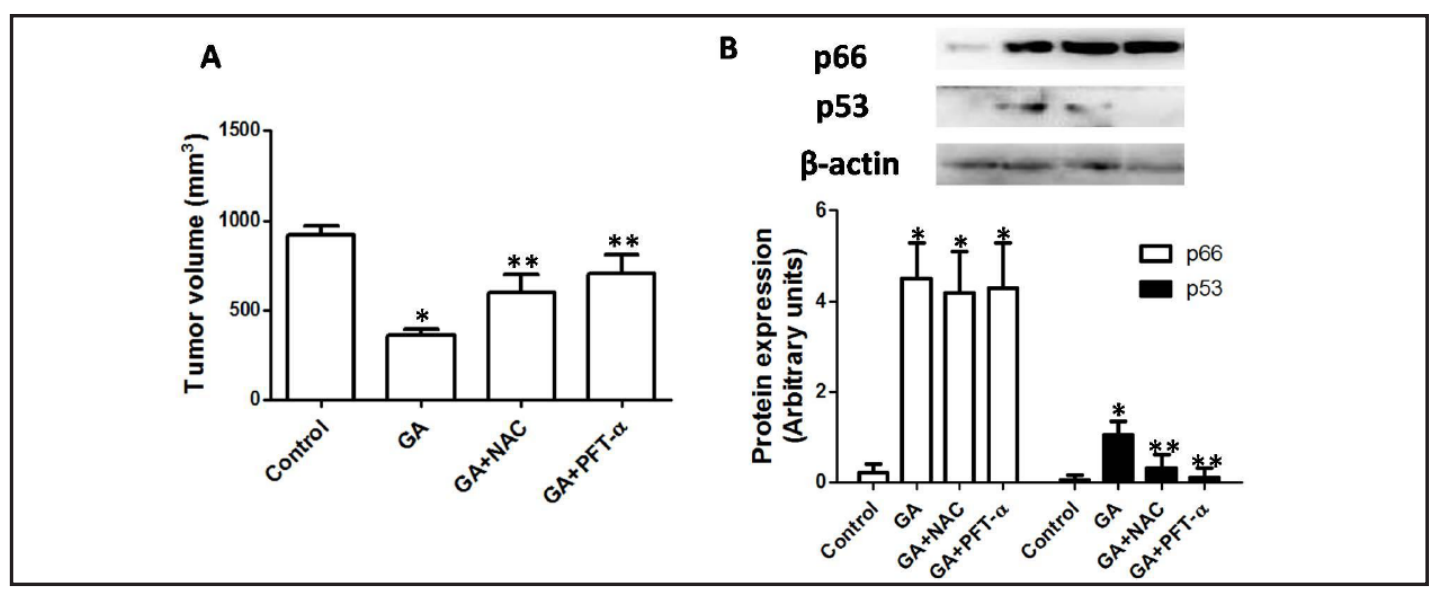

Fig. 5. Antitumor effect of GA in vivo. A375 tumor-bearing nude mice were given $100 \mathrm{mg} / \mathrm{kg}$ GA intraperitoneally, with or without $10 \mathrm{mg} / \mathrm{kg}$ NAC or $10 \mathrm{mg} / \mathrm{kg}$ PFT- $\alpha$. Control mice received vehicle (10\% DMSO, $15 \%$ ethanol and $75 \%$ PBS). After the experiment, tumor volume was measured (A). Protein expression of p66 $6^{\text {shc }}$ and p53 was determined by western blot. A representative blot was shown and results were expressed as ratio of the p66 $6^{\text {shc }}$ or $\mathrm{p} 53$ band to the $\beta$-actin band. ${ }^{*} P<0.05$, compared with Control. ${ }^{* *} P<0.05$, compared with GA.

generation, A375 cells were incubated with sip66 $6^{\text {shc }}$, and then exposed to $10 \mu \mathrm{g} / \mathrm{ml} \mathrm{GA}$ for 24 h. Sip66 $6^{\text {shc }}$ alone did not significantly affect cell viability and apoptosis (Fig. 2E, F and G), but significantly decreased ROS level in GA-treated cells (Fig. 2E), inhibited GA-induced decrease of cell viability (Fig. 2F) and increase of apoptosis (Fig. 2G). These results indicated that upregulation of $\mathrm{p}^{\text {shc }}$ was involved in GA-induced ROS generation in A375 cells, and this contributed to the decrease of cell viability and increase of apoptosis.

p6 $66^{\text {shc }}$ upregulation is involved in GA-induced mitochondrial dysfunction in A375 cells

To examine the mechanism of GA-induced apoptosis, we the effect of GA on the mitochondrial function in A375 cells was investigated. The oxygen consumption rate and Rho123 fluorescence were decreased by $10 \mu \mathrm{g} / \mathrm{ml} \mathrm{GA} \mathrm{(Fig.} \mathrm{3A} \mathrm{and} \mathrm{3B).} \mathrm{Accordingly,}$ results indicated that GA induced notable mitochondrial dysfunction in human malignant melanoma A375 cells. Inhibition of p66 $6^{\text {shc }}$ by siRNAs markedly blocked GA-induced decrease of mitochondrial function and MMP, as evidenced by the increase of oxygen consumption rate and Rho123 fluorescence intensity. Results indicated that p66 ${ }^{\text {shc }}$-mediated ROS generation may be involved in GA-induced mitochondrial dysfunction, which greatly contributed to apoptosis of A375 cells.

p53 upregulation is involved in GA-induced mitochondrial dysfunction and apoptosis in A375 cells

To test the molecular mechanism of p66 $6^{\text {shc }}$ in-ROS-mediated mitochondrial apoptosis induced by GA, p53 expression changes were evaluated in A375 cells. As shown in Fig. $4 \mathrm{~A}$ and $\mathrm{B}, \mathrm{mRNA}$ and protein expression of p53 were increased by GA in a concentrationdependent manner. When cells were treated with sip66 or $100 \mu \mathrm{M}$ NAC, a potent antioxidant, GA-induced increase of mRNA and protein expression of p53 was inhibited (Fig. 4C and D), indicating that $\mathrm{p} 66^{\mathrm{shc}}$-generated ROS was responsible for GA-induced increase of $\mathrm{p} 53$. We tested further the effect of GA on BCL2-associated X Protein (Bax). Results showed that GA concentration-dependently upregulated mRNA expression of Bax (Fig. 4E). To test whether p53 was involved in GA-induced upregulation of Bax, cells were treated with sip53. As presented in Fig. 4F, GA-induced upregulation of Bax was notably reduced in the presence of sip53, indicating that GA upregulated Bax through increasing p53. To further confirm the transcriptional regulation of Bax by GA, luciferase and CHIP assays were conducted. As shown in Fig. 4G, GA increased p53-TA-luciferase activity, which in turn was inhibited by sip53. We 


\section{Cellular Physiology Cell Physiol Biochem 2016;38:1618-1630

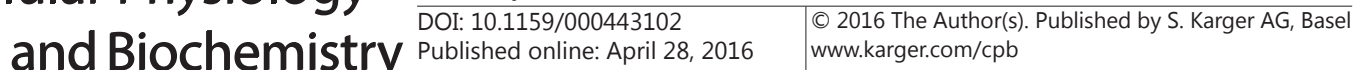 \\ Liang/Zhang: Gambogic Acid Inhibits Melanoma via P66-ROS-p53 Pathway}

showed that GA increased p53 binding to Bax promoter, and silence of p53 by siRNAs notably limited p53-Bax promoter binding (Fig. 4H). Furthermore, the role of p53 in GA-induced mitochondrial dysfunction, apoptosis and decrease of cell viability was examined. Silence of p53 by siRNAs markedly blocked GA-induced decrease of oxygen consumption rate (Fig. 4I); GA-induced decrease of cell viability and increase of apoptosis were notably inhibited by sip53 (Fig. 4J and H). These results indicated that p53 upregulation was responsible, at least partly, for GA-induced mitochondrial dysfunction, decrease of cell viability and increase of apoptosis, via transcriptional regulation of Bax.

\section{Anti-melanoma effect of GA in transplanted mice tumor model}

To investigate the inhibitory effect of GA on malignant melanoma in vivo, we established a transplanted tumor model in nude mice using A375 cells. The tumor volume was calculated to evaluate the general inhibitory effect of GA on tumor growth. Intraperitoneal injection of $100 \mathrm{mg} / \mathrm{kg}$ GA decreased tumor volume to about $40 \%$ of Control (Fig. 5A), confirming in vivo the anti-melanoma effect of GA evidenced in vitro. NAC and PFT- $\alpha$ treatment suppressed the inhibitory effect exerted by GA on tumor growth, indicating that ROS generation and p53 upregulation may be involved in the anti-melanoma effect of GA in vivo. Moreover, we showed that GA increased both p66 shc and p53 expression in tumors (Fig. 5B), but NAC and PFT- $\alpha$ treatment did not significantly affect $\mathrm{p} 66^{\text {shc }}$ expression in tumors of GA-treated mice. In contrast, both NAC and PFT- $\alpha$ treatment inhibited GA-induced p53 expression in A375 tumors transplanted in nude mice. Consistent with the in vitro obtained results, in vivo data indicated that upregulation of $\mathrm{p} 66^{\text {shc }}$ by GA caused ROS generation which contributed to the increase of p53, resulting in inhibition of tumor growth in vivo.

\section{Discussion}

Numerous studies have shown the antitumor effect of GA in various types of cancers. Recently, it was found that GA also exerted an inhibitory effect on malignant melanoma. In the current study, we further investigated in vitro and in vivo mechanisms underlying the antitumor effect exerted by GA in preclinical models of human malignant melanoma.

Consistent with previous findings, we found that GA exerted an important inhibitory effect on human malignant melanoma A375 cells in vitro and in the corresponding mouse tumor model, as evidenced by the decrease of cell viability and increase of apoptosis in A375 cells, along with inhibition of tumor growth in nude mice. It is well-known that large amounts of ROS, above a tumor-specific threshold, can induce inhibition of tumor cell proliferation and tumor growth [25-27]. Previous studies have shown that GA could promote ROS generation in various types of cancer cells. Zhen et al. [28] found that GA lysinate induced apoptosis in breast cancer MCF-7 cells by increasing ROS levels. Yang et al. [16] showed that GA enhanced the radio-sensitivity of human esophageal cancer cells by inducing ROS generation. It was also found that ROS-mediated autophagy induced by dysregulation of lipid metabolism plays a protective role in colorectal cancer cells treated with GA [29]. Consistent with previous results, we found that GA concentration-dependently increased intracellular and mitochondrial ROS generation in A375 cells. ROS could be produced by various cellular sources, including NADPH oxidases, mitochondrial oxidative metabolism, endoplasmic reticulum stress, etc [30]. Among them, mitochondria are the main source of ROS production and also the main target of ROS insult [31-33]. Recent researches have shown that $\mathrm{p} 66^{\text {shc }}$ plays a key role in mitochondrial ROS metabolism and oxidative stress response [34]. p66 $6^{\text {shc }}$ is a proapoptotic protein involved in ROS production in mitochondria, leading to mitochondrial damage and apoptosis [35]. We found that GA increased p66 $6^{\text {shc }}$ expression in human malignant melanoma A375 cells both in vitro and in vivo. Our results indicated that $\mathrm{p} 66^{\text {shc }}$ was a major target of GA, which was responsible for ROS production, hence contributing to mitochondrial dysfunction, apoptosis and decrease of cell viability in melanoma cells. 


\section{Cellular Physiology Cell Physiol Biochem 2016;38:1618-1630

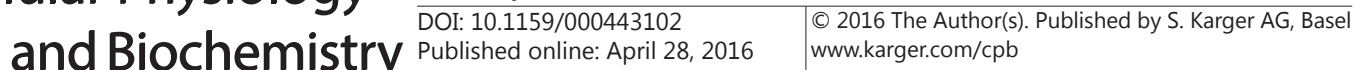 \\ Liang/Zhang: Gambogic Acid Inhibits Melanoma via P66-ROS-p53 Pathway}

The tumor suppressor protein p53 is a well-known redox-sensitive transcription factor that organizes and directs cellular functions in response to a variety of intracellular or extracellular stresses [36, 37]. ROS function as both upstream signal that activates p53, and downstream factor that mediates apoptosis [36, 37]. p53 induces mitochondrial outer membrane permeabilization by direct interaction with Bcl-2 proteins that are present in the mitochondrial outer membrane [38]. Previous studies have shown that p53 is a direct Bax activator [39]. It was found that GA induced apoptosis through p53 activation in several cancer cell lines [40, 41]. Xu et al. showed that GA induced mitochondria-dependent apoptosis by modulation of Bcl-2 and Bax in mantle cell lymphoma JeKo-1 cells [42] and in human malignant melanoma A375 cells [19]. The present study demonstrated that p53 mediated GA-induced mitochondrial dysfunction and apoptosis through transcriptional regulation of Bax, and p66 $6^{\text {shc }}$-mediated ROS generation acted as upstream signal of p53/ Bax-regulated apoptosis induced by GA.

Concluding, in the present preclinical study we found that GA increased $p 66^{\text {shc }}$ and promoted ROS generation, activated p53 and its regulation of Bax, hence leading to apoptosis and inhibition of proliferation in human malignant melanoma A375cells (schematic mechanism presented in Fig. 6). Results provided novel insights into the chemotherapeutic use of GA by highlighting the importance of $\mathrm{p} 66^{\text {shc }} /$ ROS-p53/Bax interconnected pathway in the antitumor effect of GA in malignant melanoma.

\section{Disclosure Statement}

None.

\section{References}

1 Hambright HG, Meng P, Kumar AP, Ghosh R: Inhibition of PI3K/AKT/mTOR axis disrupts oxidative stressmediated survival of melanoma cells. Oncotarget 2015;6:7195-7208.

2 Wadasadawala T, Trivedi S, Gupta T, Epari S, Jalali R: The diagnostic dilemma of primary central nervous system melanoma. J Clin Neurosci 2010;17:1014-1017.

3 Zhang C, Yuan XR, Li HY, Zhao ZJ, Liao YW, Wang XY, Su J, Sang SS, Liu Q: Anti-cancer effect of metabotropic glutamate receptor 1 inhibition in human glioma U87 cells: Involvement of PI3K/Akt/mTOR pathway. Cell Physiol Biochem 2015;35:419-432.

4 Cai T, Kuang Y, Zhang C, Zhang Z, Chen L, Li B, Li Y, Wang Y, Yang H, Han Q, Zhu Y: Glucose-6-phosphate dehydrogenase and NADPH oxidase 4 control STAT3 activity in melanoma cells through a pathway involving reactive oxygen species, c-SRC and SHP2. Am J Cancer Res 2015;5:1610-1620.

5 Carpinteiro A, Beckmann N, Seitz A, Hessler G, Wilker B, Soddemann M, Helfrich I, Edelmann B, Gulbins E, Becker KA: Role of acid Sphingomyelinase-Induced signaling in melanoma cells for hematogenous tumor metastasis. Cell Physiol Biochem 2016;38:1-14.

6 Zhu Y, Lai X, Zhao S, Zheng J, Wang X, Weng X, Li J, Ye Y, Chen Q, Lin X: Antitumor enhancement by irradiated haploidentical donor lymphocyte infusion of mice with melanoma. Cell Physiol Biochem 2015;35:2181-2191.

7 Kemper K, Krijgsman O, Cornelissen-Steijger P, Shahrabi A, Weeber F, Song JY, Kuilman T, Vis DJ, Wessels LF, Voest EE, Schumacher TN, Blank CU, Adams DJ, Haanen JB, Peeper DS: Intra- and inter-tumor heterogeneity in a vemurafenib-resistant melanoma patient and derived xenografts. Embo Mol Med 2015;7:1104-1118.

8 Partl R, Fastner G, Kaiser J, Kronhuber E, Cetin-Strohmer K, Steffal C, Bohmer-Breitfelder B, Mayer J, Avian A, Berghold A: KPS/LDH index: A simple tool for identifying patients with metastatic melanoma who are unlikely to benefit from palliative whole brain radiotherapy. Support Care Cancer 2016;24:523-528.

9 Massi D, Brusa D, Merelli B, Falcone C, Xue G, Carobbio A, Nassini R, Baroni G, Tamborini E, Cattaneo L, Audrito V, Deaglio S, Mandala M: The status of PD-L1 and tumor-infiltrating immune cells predict resistance and poor prognosis in BRAFi-treated melanoma patients harboring mutant BRAFV600. Ann Oncol 2015;26:1980-1987. 


\section{Cellular Physiology Cell Physiol Biochem 2016;38:1618-1630 and Biochemistry Published online: April 28, $2016 \quad \begin{aligned} & \text { DOI: 10.1159/000443102 } 2016 \text { The Author(s). Published by S. Karger AG, Basel } \\ & \text { www.karger.com/cpb }\end{aligned}$ \\ Liang/Zhang: Gambogic Acid Inhibits Melanoma via P66-ROS-p53 Pathway}

10 Marquez F, Babio N, Bullo M, Salas-Salvado J: Evaluation of the safety and efficacy of hydroxycitric acid or Garcinia cambogia extracts in humans. Crit Rev Food Sci Nutr 2012;52:585-594.

11 Panthong A, Norkaew P, Kanjanapothi D, Taesotikul T, Anantachoke N, Reutrakul V: Anti-inflammatory, analgesic and antipyretic activities of the extract of gamboge from Garcinia hanburyi Hook f. J Ethnopharmacol 2007;111:335-340.

12 Yi T, Yi Z, Cho SG, Luo J, Pandey MK, Aggarwal BB, Liu M: Gambogic acid inhibits angiogenesis and prostate tumor growth by suppressing vascular endothelial growth factor receptor 2 signaling. Cancer Res 2008;68:1843-1850.

13 Wang C, Zhang H, Chen Y, Shi F, Chen B: Gambogic acid-loaded magnetic Fe(3)O(4) nanoparticles inhibit Panc-1 pancreatic cancer cell proliferation and migration by inactivating transcription factor ETS1. Int J Nanomedicine 2012;7:781-787.

14 Yue Q, Feng L, Cao B, Liu M, Zhang D, Wu W, Jiang B, Yang M, Liu X, Guo D: Proteomic analysis revealed the important role of vimentin in human cervical carcinoma HeLa cells treated with gambogic acid. Mol Cell Proteomics 2016;15:26-44.

15 Wen C, Huang L, Chen J, Lin M, Li W, Lu B, Rutnam ZJ, Iwamoto A, Wang Z, Yang X, Liu H: Gambogic acid inhibits growth, induces apoptosis, and overcomes drug resistance in human colorectal cancer cells. Int J Oncol 2015;47:1663-1671.

16 Yang Y, Sun X, Yang Y, Yang X, Zhu H, Dai S, Chen X, Zhang H, Guo Q, Song Y, Wang F, Cheng H, Sun X: Gambogic acid enhances the radiosensitivity of human esophageal cancer cells by inducing reactive oxygen species via targeting Akt/mTOR pathway. Tumour Biol DOI:10.1007/s13277-015-3974-1.

17 Ma J, Ma Y, Liu X, Chen S, Liu C, Qin A, Fan S: Gambogic acid inhibits osteoclast formation and ovariectomyinduced osteoporosis by suppressing the JNK, p38 and Akt signalling pathways. Biochem J 2015;469:399408.

18 Chi Y, Zhan XK, Yu H, Xie GR, Wang ZZ, Xiao W, Wang YG, Xiong FX, Hu JF, Yang L, Cui CX, Wang JW: An open-labeled, randomized, multicenter phase IIa study of gambogic acid injection for advanced malignant tumors. Chin Med J (Engl) 2013;126:1642-1646.

19 Xu X, Liu Y, Wang L, He J, Zhang H, Chen X, Li Y, Yang J, Tao J: Gambogic acid induces apoptosis by regulating the expression of Bax and Bcl-2 and enhancing caspase-3 activity in human malignant melanoma A375 cells. Int J Dermatol 2009;48:186-192.

20 Zhao J, Qi Q, Yang Y, Gu HY, Lu N, Liu W, Wang W, Qiang L, Zhang LB, You QD, Guo QL: Inhibition of alpha(4) integrin mediated adhesion was involved in the reduction of B16-F10 melanoma cells lung colonization in C57BL/6 mice treated with gambogic acid. Eur J Pharmacol 2008;589:127-131.

21 Ma W, Hu J, Cheng Y, Wang J, Zhang X, Xu M: Ginkgolide B protects against cisplatin-induced ototoxicity: Enhancement of Akt-Nrf2-HO-1 signaling and reduction of NADPH oxidase. Cancer Chemother Pharmacol 2015;75:949-959.

22 Hu Z, Fan H, Lv G, Zhou Q, Yang B, Zheng J, Cao W: 5-Aminolevulinic acid-mediated sonodynamic therapy induces anti-tumor effects in malignant melanoma via p53-miR-34a-Sirt1 axis. J Dermatol Sci 2015;79:155162.

23 Voss MJ, Niggemann B, Zanker KS, Entschladen F: Tumour reactions to hypoxia. Curr Mol Med 2010;10:381-386.

24 Trinei M, Migliaccio E, Bernardi P, Paolucci F, Pelicci P, Giorgio M: P66Shc, mitochondria, and the generation of reactive oxygen species. Methods Enzymol 2013;528:99-110.

25 Tong L, Chuang CC, Wu S, Zuo L: Reactive oxygen species in redox cancer therapy. Cancer Lett 2015;367:1825.

26 Manda G, Isvoranu G, Comanescu MV, Manea A, Debelec BB, Korkmaz KS: The redox biology network in cancer pathophysiology and therapeutics. Redox Biol 2015;5:347-357.

27 Ibanez IL, Notcovich C, Catalano PN, Bellino MG, Duran H: The redox-active nanomaterial toolbox for cancer therapy. Cancer Lett 2015;359:9-19.

28 Zhen YZ, Lin YJ, Li KJ, Yang XS, Zhao YF, Wei J, Wei JB, Hu G: Gambogic Acid lysinate induces apoptosis in breast cancer mcf-7 cells by increasing reactive oxygen species. Evid Based Complement Alternat Med 2015;2015:842091.

29 Zhang H, Lei Y, Yuan P, Li L, Luo C, Gao R, Tian J, Feng Z, Nice EC, Sun J: ROS-mediated autophagy induced by dysregulation of lipid metabolism plays a protective role in colorectal cancer cells treated with gambogic acid. Plos One 2014; 9:e96418. 


\section{Cellular Physiology Cell Physiol Biochem 2016;38:1618-1630 \begin{tabular}{l|l} 
DOI: 10.1159/000443102 & $\begin{array}{l}\text { O 2016 The Author(s). Published by S. Karger AG, Basel } \\
\text { www.karger.com/cpb }\end{array}$
\end{tabular} \\ Liang/Zhang: Gambogic Acid Inhibits Melanoma via P66-ROS-p53 Pathway}

30 Wang X, Tao L, Hai CX: Redox-regulating role of insulin: The essence of insulin effect. Mol Cell Endocrinol 2011;349:111-127.

31 Okon IS, Zou MH: Mitochondrial ROS and cancer drug resistance: Implications for therapy. Pharmacol Res 2015;100:170-174.

32 Oyewole AO, Birch-Machin MA: Mitochondria-targeted antioxidants. Faseb J 2015;29:4766-4771.

33 Willems PH, Rossignol R, Dieteren CE, Murphy MP, Koopman WJ: Redox homeostasis and mitochondrial dynamics. Cell Metab 2015;22:207-218.

34 Migliaccio E, Giorgio M, Mele S, Pelicci G, Reboldi P, Pandolfi PP, Lanfrancone L, Pelicci PG: The p66shc adaptor protein controls oxidative stress response and life span in mammals. Nature 1999;402:309-313.

35 Ray PD, Huang BW, Tsuji Y: Reactive oxygen species (ROS) homeostasis and redox regulation in cellular signaling. Cell Signal 2012;24:981-990.

36 Liu B, Chen Y, St CD: ROS and p53: A versatile partnership. Free Radic Biol Med 2008;44:1529-1535.

37 Maillet A, Pervaiz S: Redox regulation of p53, redox effectors regulated by p53: A subtle balance. Antioxid Redox Signal 2012;16:1285-1294.

38 Galluzzi L, Morselli E, Kepp 0, Tajeddine N, Kroemer G: Targeting p53 to mitochondria for cancer therapy. Cell Cycle 2008;7:1949-1955.

39 Zheng JH, Viacava FA, Kriwacki RW, Moldoveanu T: Discoveries and controversies in BCL-2 proteinmediated apoptosis. Febs J DOI:10.1111/febs.13527.

40 Gu H, Rao S, Zhao J, Wang J, Mu R, Rong J, Tao L, Qi Q, You Q, Guo Q: Gambogic acid reduced bcl-2 expression via p53 in human breast MCF-7 cancer cells. J Cancer Res Clin Oncol 2009;135:1777-1782.

41 Gu H, Wang X, Rao S, Wang J, Zhao J, Ren FL, Mu R, Yang Y, Qi Q, Liu W, Lu N, Ling H, You Q, Guo Q: Gambogic acid mediates apoptosis as a p53 inducer through down-regulation of $\mathrm{mdm} 2$ in wild-type p53-expressing cancer cells. Mol Cancer Ther 2008;7:3298-3305.

$42 \mathrm{Xu}$ J, Zhou M, Ouyang J, Wang J, Zhang Q, Xu Y, Xu Y, Zhang Q, Xu X, Zeng H: Gambogic acid induces mitochondria-dependent apoptosis by modulation of Bcl-2 and Bax in mantle cell lymphoma JeKo-1 cells. Chin J Cancer Res 2013;25:183-191. 